direct and indirect evidence to estimate the difference between the three treatment groups on ESS. Meta-regression was used to assess the influence of CPAP usage and average baseline patient characteristics on the effect of CPAP compared to ICs.

Findings A total of 67 studies comprising 6873 patients were included in the meta-analysis. Of these, 51 (5898 patients) assessed CPAP against an IC. CPAP and MADs were estimated to reduce ESS by 2.5 (95\% CI 2.1,2.9) and 1.7 (95\% CI 1.1,2.3) points respectively compared to an IC. CPAP was estimated to reduce the ESS by a further 0.8 points compared to MADs (95\% CI 0.1,1.4; $\mathrm{p}=0.015)$. However, there was some suggestion of publication bias in favour of CPAP which may have inflated this effect. There was no evidence that studies reporting higher CPAP usage also reported larger treatment effects.

Interpretation Both CPAP and MADs are effective treatments for reducing daytime sleepiness in patients with OSA. CPAP appears to be the most effective treatment and should be recommended for more severe or sleepier OSA patients. However, MADs are a suitable second-line treatment should CPAP not be tolerated.

\section{P118 FACTORS AFFECTING CONCORDANCE WITH CONTINUOUS POSITIVE AIRWAY PRESSURE (CPAP) IN OBSTRUCTIVE SLEEP APNOEA SYNDROME (OSAS)}

${ }^{1} \mathrm{~N}$ Shilliday, ${ }^{1} \mathrm{~A}$ Bishopp, ${ }^{2} \mathrm{~B}$ Chakraborty, ${ }^{1} \mathrm{M}$ Daniels, ${ }^{1} \mathrm{R}$ Mukherjee. ${ }^{1}$ Birmingham Heartlands Hospital, Birmingham, UK; ${ }^{2}$ School of Mathematics, University of Birmingham, Birmingham, UK

\subsection{6/thoraxjn-2015-207770.255}

Introduction and objectives The benefits of continuous positive airways pressure in the treatment of obstructive sleep apnoea syndrome have been well established. Despite this, CPAP adherence remains a significant issue resulting in many patients not receiving adequate treatment. A number of variables have been suggested as contributing to non-concordance, however study results have been inconsistent. Studies assessing long term concordance, suggest severity of OSAS and sleepiness to be good predictors of this. This scientific survey looked at the influence of co-morbidity and the severity of OSAS as represented by apnoea hypopnoea index (AHI) at diagnosis on the usage and concordance with CPAP.

Methods Data from 230 patients completing annual follow up after initiation of CPAP by $31^{\text {st }}$ December 2014 was collected retrospectively. The presence and severity of co-morbidity was assessed by the Adult Co-morbidity Evaluation- 27 (ACE-27) score. CPAP usage per day was averaged over the preceding year. The association between usage and initial AHI (data available for 207 patients) was analysed by linear regression. The association between usage and ACE-27 score was analysed by ANOVA.

Results The regression coefficient for initial AHI against CPAP usage shows a statistically significant effect $([p=0.00126]$ fitted equation: concordance $=4.161+0.024 \times \mathrm{AHI}$ ). There was no significant difference in CPAP usage between different ACE-27 groups. Further analysis of individual co-morbidities revealed significance in four categories; cardiac arrhythmia $(\mathrm{p}=0.031)$, coronary artery disease $(\mathrm{p}=0.006)$, congestive heart failure $(\mathrm{p}=$ $0.045)$ and malignancy $(\mathrm{p}=0.001)$.

Conclusion AHI at diagnosis remains a strong determinant of CPAP concordance at 1 year. Severity of co-morbidity cannot be conclusively demonstrated to influence usage however further studies into overall and specific co-morbidities are warranted.

\section{Phenotypes and response to treatment in COPD}

\section{P119 CHARACTERISING NON-EOSINOPHILIC COPD}

${ }^{1} \mathrm{~K}$ Hambleton, ${ }^{1} \mathrm{REK}$ Russell, ${ }^{2} \mathrm{CE}$ Brightling, ${ }^{1} \mathrm{M}$ Bafadhel. 'Nuffield Department of Medicine, University of Oxford, Oxford, UK; ${ }^{2}$ University of Leicester, Leicester, UK

\subsection{6/thoraxjnl-2015-207770.256}

Background Phenotypes of COPD are increasingly recognised, with classification centred on inflammation and in particular microbes and inflammatory markers within the airways and peripheral blood. Studies focusing on eosinophilic inflammation in COPD have shown the validity of airway and peripheral eosinophilia as a marker to direct treatment with corticosteroids. However, the majority of COPD patients have low sputum and peripheral eosinophils, with a large proportion showing raised sputum neutrophils at exacerbation and stable state. The characteristics of this 'Non-eosinophilic' group are less well defined, making the identification of biomarkers and target pathways for drug development more challenging.

Methods Baseline data from patients with COPD, previously recruited to a study identifying biomarkers was analysed using SPSS (SPSS version 22, IBM Corp, released 2013, Armonk, NY). A cut off of $3 \%$ sputum eosinophils was used to distinguish 'Eosinophilic' and 'Non-eosinophilic' groups. Parametric and non-parametric analyses were performed where appropriate.

Results Of 149 patients, 96 had $<3 \%$ sputum eosinophils, with a median age of 69.5 years (47-88 range). There were no differences in gender and proportion of smokers between the two groups. There was an increase in percentage sputum neutrophils in the non-eosinophilic group (mean difference 15\%, 95\% confidence interval $9-17 \%, \mathrm{p}=0.01$ ). The non-eosinophilic patients had more exacerbations/person/year compared to the eosinophilic group (3.52 vs. 3.11); this was independent of inhaled corticosteroid use. There were more significant co-morbidities in the non-eosinophilic group compared to the non-eosinophilic group $(78 \%$ vs. $61 \%, \mathrm{p}<0.01)$. Co-morbidity was defined as the presence of cardiovascular disease, endocrine disorders, depression, or musculoskeletal disease.

There were more positive sputum cultures in the non-eosinophilic group compared to the eosinophilic group (33\% vs. $11 \%$, $\mathrm{p}=0.16)$. There was also an increase in colony forming units in the non-eosinophilic group compared to the eosinophilic group (mean fold difference $0.4,95 \%$ CI $0-0.8, \mathrm{p}=0.05$ ).

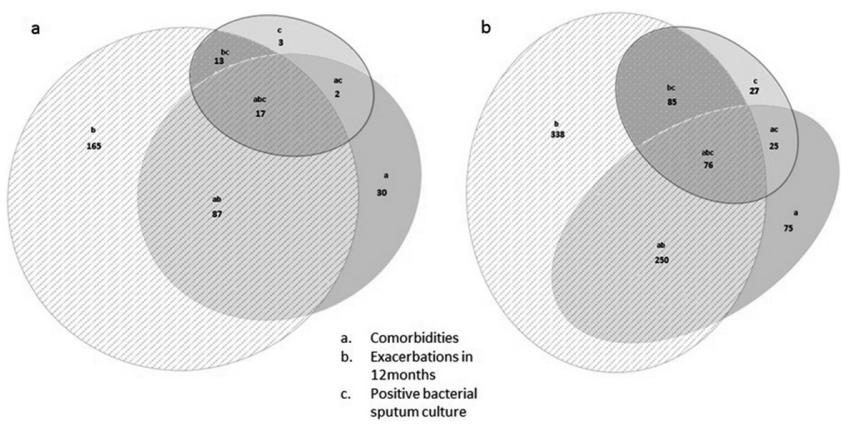

Abstract P119 Figure 1 Venn digram showing relationship of characteristics of eosinophilic (a) and non-eosinophilic (b) COPD, using absolute numbers 
Conclusions Non-eosinophilic COPD subjects have more exacerbations, with more co-morbidities and bacterial burden (see Figure 1). Further work is required to understand the pathogenesis of this phenotype.

\section{P120 REAL LIFE DISTRIBUTION OF COPD SEVERITY IN THE GERMAN DACCORD REGISTRY: LUNG FUNCTION IS THE MAIN DRIVER OF CLASSIFICATION IN GOLD GROUP C AND D}

${ }^{1} \mathrm{H}$ Worth, ${ }^{2} \mathrm{R}$ Buhl, ${ }^{3} \mathrm{C}-\mathrm{P}$ Criee,,${ }^{1} \mathrm{P}$ Kardos, ${ }^{4} \mathrm{C}$ Mailaender, ${ }^{5} \mathrm{CF}$ Vogelmeier. ${ }^{1}$ Facharztforum Fuerth, Fuerth, Germany; ${ }^{2}$ Pulmonary Department, Mainz University Hospital, Mainz, Germany; ${ }^{3}$ Department of Sleep and Respiratory Medicine, Evangelical Hospital GoettingenWeende, Bovenden, Germany; ${ }^{4}$ Novartis Pharma GmbH, Nuermberg, Germany; ${ }^{5}$ Department of Respiratory Diseases, University of Marburg, Marburg, Germany

\subsection{6/thoraxjn-2015-207770.257}

Introduction Currently there is limited real-life data available regarding the distribution of COPD patients using the GOLD 2011 criteria. The German DACCORD registry that collects data from a large 'real life' population sample was used to categorise COPD patients according to GOLD 2011.

Methods To be eligible for entry into DACCORD, all patients had to have a diagnosis of COPD (consistent with the German Disease Management Programme definition), and, prior to entry, had to have either newly initiated bronchodilator maintenance medication, or to have a bronchodilator added to their maintenance regimen. No other inclusion criteria were applied, and the only exclusion criterion was a diagnosis of asthma. In primary and secondary care, data were collected from 4,123 COPD outpatients, including spirometry, exacerbations, CAT and mMRC. Results The mean age of patients was 65.7 years with $40.3 \%$ of patients still working and $73.3 \%$ patients with duration of disease $\geq 1$ year.

Based on mMRC $0-1,37.2 \%$ of patients had few symptoms (A and C); using CAT $<10$, only $9.0 \%$ were categorised into these two groups. $32.5 \%$ of the patients were assigned to $\mathrm{C}$ and D groups solely due to FEV1 $<50 \%$.

After 12 months, $41.4 \%$ patients in GOLD A were categorised in a higher GOLD category, while $42.7 \%$ of GOLD D patients were categorised in a lower GOLD category (GOLD categorization based on CAT). $67.6 \%$ of patients categorised as D at baseline due to exacerbation history alone were categorised as GOLD B after 1 year follow-up.

Almost $80 \%$ of GOLD B patients were still categorised as GOLD B after the observation period of 12 months and were therefore the most stable subgroup with regards to COPD severity according to GOLD 2011 (Figure 1).

\begin{tabular}{|c|c|c|c|c|c|c|c|}
\hline & \multicolumn{6}{|c|}{ GOLD 2011 at 12 months } \\
\hline & & A & B & C & $\mathrm{D}^{*}{ }^{*}$ & $\mathrm{D}^{*}{ }^{2}$ & D3* \\
\hline & $\begin{array}{r}\mathrm{N} \\
\text { (\% of total) }\end{array}$ & \begin{tabular}{|l|}
370 \\
$(9.4 \%)$
\end{tabular} & $\begin{array}{l}2144 \\
(54.3 \%)\end{array}$ & $\begin{array}{l}139 \\
(3.5 \%)\end{array}$ & $\begin{array}{l}936 \\
(23.7 \%)\end{array}$ & $\begin{array}{l}169 \\
(4.3 \%)\end{array}$ & $\begin{array}{l}169 \\
(4.3 \%)\end{array}$ \\
\hline A & $\begin{array}{l}\mathbf{2 3 2} \\
(5.9 \%)\end{array}$ & \begin{tabular}{|l|}
136 \\
$(3.4 \%)$
\end{tabular} & $\begin{array}{l}68 \\
(1.7 \%)\end{array}$ & $\begin{array}{l}16 \\
(<1 \%)\end{array}$ & $\begin{array}{l}7 \\
(<1 \%)\end{array}$ & $\begin{array}{l}2 \\
(<1 \%)\end{array}$ & $\begin{array}{l}2 \\
(<1 \%)\end{array}$ \\
\hline B & $\begin{array}{l}\mathbf{1 7 7 4} \\
(44.9 \%)\end{array}$ & \begin{tabular}{|l|}
142 \\
$(3.6 \%)$
\end{tabular} & $\begin{array}{l}1419 \\
(35,9 \% \%)\end{array}$ & $\begin{array}{l}15 \\
\text { (<1\%) }\end{array}$ & $\begin{array}{l}114 \\
(2.9 \%) \\
\end{array}$ & $\begin{array}{l}68 \\
(1.7 \%)\end{array}$ & $\begin{array}{l}17 \\
(<1 \%)\end{array}$ \\
\hline c & $\begin{array}{l}124 \\
(3.1 \%)\end{array}$ & \begin{tabular}{|l}
30 \\
$(<1 \%)$
\end{tabular} & $\begin{array}{l}14 \\
(<1 \%)\end{array}$ & \begin{tabular}{|l|}
39 \\
$(<1 \%)$
\end{tabular} & $\begin{array}{l}32 \\
(<1 \%)\end{array}$ & $\begin{array}{l}7 \\
(<1 \%)\end{array}$ & $\begin{array}{l}2 \\
(1 \%)\end{array}$ \\
\hline $\mathrm{D} 1^{*}$ & $\begin{array}{l}865 \\
(21.9 \%)\end{array}$ & \begin{tabular}{|l|}
33 \\
$(<1 \%)$ \\
\end{tabular} & $\begin{array}{l}176 \\
(4.5 \%) \\
\end{array}$ & $\begin{array}{l}42 \\
(1.0 \%) \\
\end{array}$ & $\begin{array}{l}553 \\
(14.0 \%) \\
\end{array}$ & $\begin{array}{l}5 \\
(<1 \%)\end{array}$ & $\begin{array}{l}59 \\
(1.5 \%) \\
\end{array}$ \\
\hline $\mathrm{D} 2 *$ & $\begin{array}{l}\mathbf{5 9 9} \\
(15.2 \%)\end{array}$ & \begin{tabular}{|l|}
32 \\
$(<1 \%)$
\end{tabular} & $\begin{array}{l}405 \\
(10.3 \%)\end{array}$ & $\begin{array}{l}12 \\
\text { (<1\%) }\end{array}$ & $\begin{array}{l}50 \\
(1.3 \%)\end{array}$ & $\begin{array}{l}76 \\
(1.9 \%)\end{array}$ & $\begin{array}{l}22 \\
(<1 \%)\end{array}$ \\
\hline D3* & $\begin{array}{l}355 \\
(9.0 \%)\end{array}$ & $\begin{array}{l}7 \\
(<1 \%)\end{array}$ & $\begin{array}{l}65 \\
(1.6 \%)\end{array}$ & $\begin{array}{l}15 \\
(<1 \%)\end{array}$ & $\begin{array}{l}181 \\
(4.5 \%)\end{array}$ & $\begin{array}{l}11 \\
(<1 \%)\end{array}$ & $\begin{array}{l}67 \\
(1.7 \%)\end{array}$ \\
\hline
\end{tabular}

Abstract P120 Figure 1
Conclusion A significant proportion of patients in the DACCORD registry are classified in GOLD C and D groups based solely on airflow limitation, in accordance with previous studies. Patients categorised as GOLD B were the most stable over the observational period of 12 months according to GOLD 2011. With the prospective collection of exacerbations over the second year of follow-up, a clearer picture of progression of GOLD 2011 categorisation might be drawn.

\section{P121 CHARACTERISTICS OF COPD PATIENTS WITH AND WITHOUT MAINTENANCE TREATMENT AT BASELINE, BY GOLD STAGE: TONADO}

${ }^{1} \mathrm{~S}$ Korn, ${ }^{2} \mathrm{R}$ Abrahams, ${ }^{3} \mathrm{~L}$ Grönke, ${ }^{4} \mathrm{~L}$ Korducki, ${ }^{3} \mathrm{VC}$ Amatto, ${ }^{1} \mathrm{R}$ Buhl. ${ }^{1}$ Pulmonary Department, Mainz University Hospital, Mainz, Germany; ${ }^{2}$ Morgantown Pulmonary Associates, Morgantown, West Virginia, USA; ${ }^{3}$ Boehringer Ingelheim Pharma GmbH \& Co. KG, Ingelheim, Germany; ${ }^{4}$ Boehringer Ingelheim Pharmaceuticals Inc., Ridgefield, Connecticut, USA

\subsection{6/thoraxjnl-2015-207770.258}

Rationale The efficacy and safety of the once-daily combination of tiotropium (T), a long-acting muscarinic antagonist (LAMA), and olodaterol $(\mathrm{O})$, a long-acting $\beta_{2}$-agonist (LABA), for the treatment of chronic obstructive pulmonary disease (COPD) has been established. We investigated whether there was a difference in the characteristics of COPD patients with and without baseline maintenance treatment.

Methods Two replicate, randomised, 52-week, double-blind, parallel-group, Phase III trials (NCT01431274; NCT01431287; n $=5162)$ assessed the efficacy and safety of once-daily treatment with $\mathrm{T}+\mathrm{O}\left(2.5 / 5 \mu \mathrm{g} ; 5 / 5 \mu \mathrm{g}\right.$; Respimat ${ }^{\circledR}$ inhaler $)$ compared to the individual components. Baseline characteristics of COPD patients within Global initiative for chronic Obstructive Lung Disease (GOLD) subgroups 2 and 3/4, with/without maintenance treatment (prior LABA, LAMA or both at baseline), are presented, based on data from the pooled set.

Results Most patients received baseline maintenance treatment (3037 vs 2121) and of those, there was a greater proportion of GOLD $3 / 4$ compared to GOLD 2 patients $(52.58 \%$ vs $47.42 \%$, respectively). An opposite trend was observed in patients not receiving maintenance treatment (GOLD 3/4, 45.87\% vs GOLD 2, 54.13\%). The proportion of current smokers was lower in GOLD 3/4 than GOLD 2 patients, as expected (Table); nevertheless, irrespective of GOLD stage, there was a greater proportion of smokers without maintenance treatment than with maintenance treatment $(42.81 \%$ vs $32.86 \%$, respectively). As expected, pulmonary function was reduced in GOLD 3/4 compared to GOLD 2 patients, although it appeared comparable between patients with and without maintenance treatment. Of the patients with maintenance treatment, a considerably greater proportion received inhaled steroids compared to those without prior LAMA/LABA treatment $(69.67 \%$ vs $15.51 \%$, respectively). Furthermore, a smaller proportion of patients without prior LAMA/LABA treatment received short-acting $\beta$-adrenergics compared to those with maintenance treatment (Table 1). Of the GOLD 3/4 patients without baseline maintenance treatment, $43.4 \%$ were not receiving any other pulmonary medication. 